\title{
IS There A PROBlem OF OTHER MiNdS?
}

\author{
Anil Gomes \\ Trinity College, University of Oxford \\ Forthcoming, Proceedings of the Aristotelian Society [accepted 2011] \\ Scepticism is sometimes expressed about whether there is any interesting \\ problem of other minds. In this paper I set out a version of the conceptual \\ problem of other minds which turns on the way in which mental \\ occurrences are presented to the subject and situate it in relation to debates \\ about our knowledge of other people's mental lives. The result is a \\ distinctive problem in the philosophy of mind concerning our relation to \\ other people.
}

\section{Introduction}

When I was a boy in graduate school, the philosophy of mind had two main divisions: the mind/ body problem and the problem of other minds... Philosophical fashions change. It's gotten harder to believe that there is a special problem about the knowledge of other minds (as opposed to other anything elses)... (Jerry Fodor, in [Guttenplan 1994, p.292])

The problem of other minds can look like a philosophical standard: one of those problems which has always been with us and about which there is always something to say. But, interestingly, that's not obviously true. In her history of the other minds problem, Anita Avramides suggests that the ancient Greeks don't exhibit any of the scepticism associated with the traditional problem of other minds. ${ }^{1}$ And even if it were true that we once 
believed there to be a problem of other minds, this belief may have been mistaken, as the above quote from Fodor attests. For the continued presence of the problem of other minds in our lectures and textbooks may owe more to historical and professional contingencies than anything philosophically distinctive about other minds as such.

Why might one be sceptical about the existence of a problem of other minds? The traditional problem of other minds is an epistemological problem about knowledge. In its most common formulation, it raises a sceptical problem about the possibility of knowing anything about another person's mental life. And one reason for doubting the existence of such a problem is the thought that there is nothing particular to our knowledge of other minds which could generate a distinctively sceptical concern.

Consider, for example, sceptical challenges to our knowledge of other minds which focus on the possibility of pretence or deception. ${ }^{2}$ It seems possible that those around me are engaged in skilful dissemblance on the model of The Truman Show, or are clever facsimiles designed to present the appearance of people with mental lives. In such cases, we lack knowledge of other people's mental lives. According to the sceptical challenge, such situations are indiscriminable from our current situation: for all we know, we could be in cases of pretence or deception. If knowing that another person has certain mental features entails the knowledge that one is not in a sceptical situation, cases of pretence and deception pose a prima facie obstacle to knowing about another's mental life.

However, if this is the way to raise the epistemological problem of other minds, then Fodor's scepticism seems appropriate. For this sceptical problem can be raised about any domain of knowledge. In the case of perceptual knowledge, it seems possible that I could be undergoing a fullblown hallucination, or that I am one of Putnam's brains in a vat. With respect to knowledge of the past, it seems possible that the world sprang into existence only five minutes ago, with all my memories included. If I can't rule out these sceptical situations, can I be said to know anything about the respective domains? The threat posed to knowledge by sceptical situations generalises more widely. ${ }^{3}$

\footnotetext{
2 [McDowell 1982, pp.380-1]

3 Drestke stresses this in [Dretske 1973, p.35].
} 
A second source for scepticism about the problem of other minds rests on a distinction made in the twentieth-century between epistemological and conceptual problems of other minds. The traditional problem of other minds is an epistemological problem about knowledge: it challenges the possibility of knowing about another's mental life. But discussions of this topic have also made reference to a conceptual problem of other minds, often traced back to Wittgenstein's Philosophical Investigations. ${ }^{4}$ This conceptual problem is one about thought: it raises a problem in accounting for our ability to think of another person as a bearer of mental states or a subject of mental events. And this concern is claimed to be distinct from any worries we might have about whether it is possible to know about her mental life.

Why would this distinction between epistemological and conceptual concerns lead to scepticism about the problem of other minds? According to some discussions of the conceptual problem, once we attend to the problem of accounting for our ability to think of another person as subject to mental phenomena, issues about the possibility of knowing about such phenomena drop out of the picture. ${ }^{5}$ The conceptual problem - it is suggested - is not only conceptually prior to the epistemological problem, its successful resolution dissolves any concerns one might have about knowledge of another person's mind. Concern with the conceptual problem overrides any problems about knowledge.

It is a combination of these two factors which, I think, accounts for the slightly neglected status of the problem of other minds in contemporary philosophical discussion. For each pulls in an opposing direction to leave a space where the problem of other minds was once discussed. For those more firmly situated in traditional epistemology and metaphysics, the problem of other minds has ceased to look like a distinctive sceptical problem, and any interesting philosophical issue which could have been raised under its heading can be addressed more widely when thinking about sceptical challenges to knowledge claims in general. Whereas those who take the conceptual problem of other minds seriously often view it as bound up with wider themes about the publicity of language and thought found in the Philosophical Investigations and its import lies as an example of broader philosophical confusions. ${ }^{6}$ The result is a side-lining of the

\footnotetext{
4 [Wittgenstein 1953]

5 [Malcolm 1958, pp.976-8]

${ }^{6}$ See, e.g., [Overgaard 2007].
} 
traditional debate about how we should conceive our relation to other people and their mental lives.

My aim in this paper is to begin the task of responding to such disciplinary scepticism. In what follows I will focus on the conceptual problem of other minds. In the first part of the paper I'll set out two alleged obstacles to our ability to think about other minds and suggest that each relies on certain philosophical assumptions. If the reasoning in support of the conceptual problem relies on these assumptions - and if philosophical fashions have changed such that these assumptions no longer look compulsory - then we have an explanation for the change in status of the problem of other minds.

In the second part of the paper I'll suggest an alternative way to formulate the conceptual problem which focuses on our experience of mental life. This problem can be avoided, I'll suggest, only by recognising the embodiment of mental phenomena. Finally I'll aim to situate this formulation in relation to traditional debates about knowledge. My hope is to show that this topic involves interesting and distinctive issues of concern.

\section{The Conceptual Problem}

How should we formulate the conceptual problem of other minds? Let us phrase the initial question as follows:

(CP): How is it possible for us to think about other minds?

So formulated, (CP) appears more basic than any concern about knowledge of other minds, for knowledge claims presuppose conceptual capabilities, and thus any problem with accounting for our ability to think about other minds will a fortiori pose a problem for explaining the possibility of our knowing about them.

Following Robert Nozick and Quassim Cassam, I will assume that such 'how-possible' questions derive their interest from prima facie obstacles to the possibility of the achievement in question. ${ }^{7}$ What is the supposed obstacle to our being able to think about other people's minds? In thinking

7 [Nozick 1981, pp.8-11, pp.13-18], [Cassam 2007, ch.1]. 
about other people's mental lives we make use of ways of thinking about mentality which can be exercised in both first- and third-person contexts. Call this the Generality Claim, and let us understand it as the assertion that subjects possess a general conception of the mental. One way of reading the conceptual problem of other minds is as claiming that there is a problem with explaining our possession of a general conception of the mental, and thus that there exists an obstacle to our thinking about other minds. ${ }^{8}$

What is the obstacle to our possession of such a conception of the mental? The first suggestion I want to consider is that the possession of such a conception is threatened by the fact that the way in which we know our own mind is different in kind from the way in which we know about the minds of other people. Call this the Knowledge Obstacle. According to this claim, the existence of distinct first- and third-personal ways of knowing presents a prima facie challenge to the possibility of possessing a general conception of the mental. One finds this suggestion in parts of Strawson: after noting the univocity of first- and third-personal uses of mental terms, for example, he writes that 'to the philosopher this thought has given trouble. How could the sense [of these terms] be the same when the method of verification was so different in the two cases...?' [Strawson 1959, pp.99-100]. The suggestion is that the generality of our mental concepts is threatened by the fact that we have different ways of coming to know whether they apply. ${ }^{9}$

One question about this proposal is whether it is true that the ways in which we know our own mind really are different in kind from the ways in which we know about the minds of others: Ryle, for instance, argues that the ways in which we find out about our own minds and the ways we find out about others' are 'differences of degree, not of kind' [Ryle 1949, 179]. A deeper concern is the assumption that the different ways we have of knowing whether a mental term applies are sufficient to determine a difference in meaning between first and third-person cases. This claim only looks plausible if one assumes that the meaning of a term is tied to the way we have of knowing whether or not it applies: is tied, that is, to the

\footnotetext{
${ }^{8}$ For reflections on the relation between a general conception of the mental and the systematicity of thought, see [Strawson 1959, pp.99-100] and [Evans 1982, p.75].

${ }^{9}$ Norman Malcolm makes a similar suggestion: [Malcolm 1958, p.70]. Cf. Davidson: 'If two concepts regularly depend for their application on different criteria or ranges of support, they must be different concepts.' [Davidson 1987, p.16]
} 
conditions for its verification. In the absence of such an assumption, there is no reason to accord this difference in knowing such a problematic status. The existence of distinct routes to knowledge only presents an obstacle to the possession of a general conception of the mental given a controversial claim linking meaning and verification. ${ }^{10}$

The second suggestion to be considered can be traced back to Wittgenstein's discussion of the relation between sensation and behaviour in the Philosophical Investigations. One of the central themes of those passages which have been thought to suggest a conceptual problem of other minds - roughly $\$ \$ 281-307$ - is the thought that there is something problematic about detaching the inner notion of sensation from its outer behavioural manifestation. If sensation is detached from behaviour - the thought goes - then there is an obstacle to explaining how we can possess a general conception of the mind. Call this the Separation Obstacle. ${ }^{11}$

What is meant by the detachment of sensation from behaviour? In some of the early statements of the conceptual problem, this concern is characterised as the claim that the relation between sensation and behaviour is only contingent. ${ }^{12}$ Later formulations address the question of whether sensations can be individuated without appeal to behaviour. ${ }^{13}$ More generally we might take Wittgenstein's target to be the claim that mental occurrences form a self-standing realm which is independent of the bodily aspects of human subjects. It is this separation which is said to present an obstacle to our possession of a general conception of the mental.

Why should the separation of sensation from behaviour present such an obstacle? According to the Mental Placement argument, it is a condition on the possession of a general conception of the mental that we conceive of mental phenomena as spatial and temporal aspects of a person, where a person is understood as a subject of both mental and physical properties. Assuming that to think of mental phenomena as spatially and temporally located is to think of them as partly individuated by behaviour, this

\footnotetext{
${ }^{10}$ Similar considerations apply to those who find an obstacle in the differing assertibility conditions for first- and third-person uses of mental terms. See [McGinn 1984, p.136], [Avramides 2001, p.224]. For a comment on Strawson's commitment to verificationism, see n.18 below.

${ }^{11}$ For presentations of the conceptual problem in this vein, see [Strawson 1959, pp.98100], [Malcolm 1958, p.975], [Williams 1978, pp.100-103; pp.294-7], [Brewer 2002, p.24], [Pickard 2003, p.87].

12 [Malcolm 1954, p.531]

13 [Pears 1988, pp.323-327]
} 
argument holds that thinking of sensation and behaviour as separate and distinct presents an obstacle to our possessing a general conception of the mental. The problematic separation is the conceptual separation of sensation and behaviour.

How does this argument proceed? Consider first what is involved in possessing a general conception of the mental. A subject who possesses a general conception of the mental has ways of thinking about other people's mental lives which she can exercise in both first- and third-person contexts. To get a sense of the competencies involved in thoughts of this kind, consider the difference between the representation 'I am in pain' and the representation 'there is pain'. According to Bernard Williams, the former represents 'a substantial state of affairs', one which can be represented 'from a third-personal point of view' [1973, pp.95-96]. In contrast, the representation 'there is pain' is a simple feature-placing sentence which makes no reference to any particular. ${ }^{14}$ In order to be capable of ascribing mental features both to herself and to others, a subject must be capable of representing to herself the more substantial state of affairs, one which goes beyond what is represented by the feature-placing sentence.

Williams's claim here is that the distinction to be drawn between substantial and feature-placing representations only makes sense within a framework which allows a third-personal perspective on the mental. One way of putting this is that the subject needs to be able to think of mental occurrences as the kind of things which can exist without being undergone by her, and this can only be provided by a framework which allows for some other perspective on mental occurrences: otherwise the idea of a mental occurrence existing without being present would make no sense. Drawing the distinction between the substantial and feature-placing representations involved in possessing a general conception of the mental requires subjects to be capable of taking up a third-personal point of view on mentality.

According to the Mental Placement argument, taking up such a view on the mental requires that we conceive of mental occurrences as located at a place. And conceiving of mental occurrences as located at a place requires thinking of them as spatial and temporal aspects of a person. Together these claims support the conclusion that possessing a general conception of

14 [Strawson 1959, p.202] 
the mental requires us to think of mental phenomena as spatial and temporal aspects of persons.

Let us take each of these claims in turn. Why should taking up a thirdpersonal view on the mental require thinking of mental occurrences as located at a place? The supporting thought is that the only way we can think of something happening but not falling within our purview is for us to conceive of it as happening (so to speak) elsewhere. This requirement turns on the fact that we need to think of mental occurrences as relativised to a location in order to understand how it can be true both that there is pain and that there is not pain: such a state of affairs can hold only because there is pain here and there is not pain over there. These placeholders serve to explain the capacity to think of mental occurrences as present but not undergone. ${ }^{15}$

So long as the notion of a place is understood purely schematically, the first part of the Mental Placement argument can be seen as simply drawing out the competencies involved in possessing a general conception of the mental. But at such a schematic level, it is hard to see why the second step should be thought to hold good. Even if we grant that taking up a thirdpersonal view on the mental requires us to conceive of mental occurrences as located, why must we locate them as spatial and temporal aspects of persons? Other alternatives might include thinking of mental occurrences as located in Cartesian souls or as causally related to, and thereby antecedently located in, particular human bodies. Neither of these options would require thinking of mental occurrences as spatial and temporal aspects of persons - and thus neither would require a rejection of the separation of sensation and behaviour alleged to pose a problem for the possession of a general conception.

Support for the second step in the argument can be drawn from Strawson's discussion of persons in his Individuals. To think of mental occurrences as located is to think of them as ascribable to something occupying a subject position. And - Strawson claims - it is a requirement on ascribing mental occurrences to the subject position that we are able to identify the subject involved. Since neither Cartesian souls nor mental occurrences antecedently located can be identified, we cannot ascribe mental occurrences to either of these locations. It is only if mental occurrences are

15 See Williams's discussion of Lichtenberg's objection: [Williams 1973, pp.95-101]. 
spatial and temporal aspects of a person that identification, and thus ascription, can take place. ${ }^{16}$

Strawson's argument makes good the second claim in the Mental Placement argument. But it raises a number of questions. The most pressing concerns the type of identification required for the ascription of mental occurrences. If identification involves some sort of perceptual differentiation, this claim is too strong: we are in general capable of ascribing mental occurrences to persons whom we are incapable of perceptually identifying, as when I think that the well-camouflaged ninjas hiding in my garden must be remarkably patient. But if identification simply means the capacity to single out an individual in thought, then it is not clear why thoughts about Cartesian souls or causally relevant bodily locations will not suffice.

Strawson expands on the kind of identification required in his commentary on Kant's Paralogisms of Pure Reason. ${ }^{17}$ The ascription of mental occurrences to something occupying the subject position requires 'empirically applicable criteria for the numerical identity through time of a subject of experiences... and these criteria, though not the same as bodily identity, involve an essential reference to the human body' [1966, p.164]. This follows from the principle of significance, the claim that 'there can be no legitimate, or even meaningful employment of ideas or concepts which does not relate them to empirical or experiential conditions of application' [1996, p.16]. It is this principle of significance which places an identification condition on mental ascription incompatible with the ascription of mental predicates to Cartesian souls.

With Strawson's argument in place, the Mental Placement argument supports the claim that the separation of sensation from behaviour presents an obstacle to our possession of a general conception of the mental. But it thus rests upon Strawson's principle of significance, a principle which evinces a link between the meaningful employment of a concept and empirical criteria for its application. It is only on the assumption that the meaningful employment of a concept requires empirical criteria of application that we have an obstacle to the possession of a general

\footnotetext{
16 [Strawson 1959, pp.99-100].

17 [Strawson 1966, pp.162-169].
} 
conception of the mental. Without this expression of verificationism, the Mental Placement argument falls short. ${ }^{18}$

We have considered two obstacles to our possession of a general conception of the mental: the Knowledge Obstacle and the Separation Obstacle. In both cases I have suggested that the obstacle in question only looks problematic given a commitment to a link between the meaning of a mental concept and its conditions of verification. The result is a philosophical problem which no longer looks compelling to those who reject such verificationism. If the conceptual problem of other minds is to prompt disquiet, an alternative account of the obstacle must be proposed.

\section{Embodiment and Mental Life}

We have considered, and rejected, two accounts of the obstacle posed to our possessing a general conception of the mental. In this section I will consider an alternative line of argument for the claim that the separation of sensation and behaviour presents such an obstacle - a line of argument which avoids verificationist commitment.

Consider the failings of the Mental Placement argument. In schematic terms, the Mental Placement argument claims that it is a necessary condition on the possession of a general conception of the mental that we think of sensations in a certain way. It thus has the form of a beliefdirected transcendental argument, and is open to the objections which have been raised to any argument of such form. ${ }^{19}$ If one finds such objections compelling, this suggests that it is a mistake to focus on the beliefs subjects must hold in order to count as possessing a general conception of the mental, for the possession of such a conception is compatible with a range of beliefs regarding the location of mental occurrences. In the rest of this paper I want to explore an alternative line of thought which emphasises not the beliefs required to possess a general conception of the mental, but the nature of the experiences involved in our mental life.

\footnotetext{
18 Strawson's arguments in [Strawson 1959] and [Strawson 1966] are often alleged to rely on some sort of verificationist principle; he admits his contentment with a certain weak form of verificationism in the final paragraph of [Strawson 1976].

${ }^{19}$ See Stroud on transcendental arguments [Stroud 1968], and Cassam on the problem of misconception [1999, pp.127-136].
} 
Here is the passage in Wittgenstein which has been the focus of discussion:

If one has to imagine someone else's pain on the model of one's own, this is none too easy a thing to do: for I have to imagine a pain which I do not feel on the model of a pain which I do feel. [PI, \$302]

There is little in this passage to suggest that its concern is the beliefs that subjects hold about the relation between sensations and behaviour. Rather, explication often runs as follows: if behaviour and sensation were distinct, then one would have to understand what it would be for a mental concept to apply to some other person purely on the basis of experiences of one's own sensations. But it is not possible to learn from one's own case what it is for a sensation to apply to another. That would be like imagining a pain which I do not feel, on the model of a pain which I do feel: none too easy a thing to do. ${ }^{20}$

How are we to understand the argument in this passage? One line of thought runs as follows. Assume that sensations are distinct from behaviour. Then sensations are not presented to the subject as modes or aspects of an individual: they are simply subjective changes in one's conscious life. But such subjective changes cannot provide the material for distinguishing between the sensation being and its being present. For there is no objective standpoint on such subjective changes which could provide the criteria for distinguishing the happening of the mental event from its happening to me. So we cannot make room within our subjectivity for the thought of another perspective onto the world. ${ }^{21}$

According to this line of thought, it is the alleged sensory awareness of sensation as independent of behaviour which presents an obstacle to our possession of a general conception of the mental. We can put the point in terms of Williams's distinction between substantial and feature-placing representations. On the proposed model of sensations, one's awareness of sensations mirrors the structure of feature-placing representations: what is given to the subject is simply the presence of pain. This sensation exhausts the content of the experiential episode. In order to be capable of thinking of such sensations as ascribable to another, there would need to be a way of thinking of them objectively, as the kinds of things which can exist

\footnotetext{
${ }^{20}$ See [Malcolm 1954, p.537-8] for an interpretation along these lines.

${ }^{21}$ This reading links the argument to Wittgenstein's concern with solipsism and the mental ego. See [Pears 2006, ch.5].
} 
elsewhere in the world. But the 'pure point of view of consciousness' [Williams 1973, p.100] makes no room for such a perspective: the only criteria for individuation and identity available are exhausted by the subject's experiential state.

One might hope to avoid this obstacle by invoking the notion of a causal relation. Say that sensations stand in causal relations to the bodily behaviour of human subjects, and that such behaviour is presented to us as a spatial and temporal aspect of our person: since we understand what it is for a pattern of behaviour to occur to someone else, one might hold that we can think of other people's sensations as simply the causal antecedents of such behaviour. This response accepts that the presentation of sensations alone couldn't provide the individuation conditions for a general mental episode but holds that the supplementation of such an account with a causal relation can avoid the problem.

This response can be interpreted in two ways. On one interpretation, it claims that we are to think of other people's sensations as whatever it is that causes certain patterns of bodily behaviour: I discuss such theory-based responses to the obstacle below. But it is sometimes suggested that the invocation of a causal relation can help us think of these felt sensations as potentially enjoyed by another. And this should be resisted. The causal relation appealed to holds between other people's sensations and their bodily behaviour. And one can grasp this causal relation only if one understands the items which are so related. This means that an understanding of what it is for another to be subject to mental sensations is required in order to grasp the causal relation itself. Without a prior understanding of what it would be for sensations to exist elsewhere in the world, we cannot begin to think of them as standing in causal relations to bodily behaviour.

We have, then, an alternative account of why the separation of sensation and behaviour presents an obstacle to our possession of a general conception of the mental. The claim is that the presentation of such sensations is not sufficient to ground our understanding of what it would be for another to be subject to mental occurrences. If sensation and behaviour are wholly detached, then sensations are not presented to us as aspects of an individual: they bear no connection to anything outside of the realm of conscious experience. But when presented in this way, there is no perspective from which we can think of them as existing independently 
of my subjective consciousness. It is the impossibility of grounding a general conception of the mental in the experience of a self-standing mental realm which presents the obstacle to our thought about other minds.

This obstacle assumes that we use the experience of sensations to ground our conception of the mental. And one way to avoid the obstacle is to deny this assumption: to deny, that is, that our understanding of the mental requires any grounding in experience. One could hold, for example, that our understanding of mental concepts is innate, obviating the need to 'learn from one's own case'. Or one could hold that our understanding of mental concepts is grounded in a tacit psychological theory which posits mental states and events as the best explanation of observed behaviour, and that first- and third-person ascriptions of mental concepts draw equally on this tacit theoretical knowledge. Both options avoid the obstacle by rejecting the assumption that our understanding of mental concepts need be grounded in experience.

This second form of denial is perhaps the best lens through which to view many of the inferential solutions proposed to explain our knowledge of other minds. ${ }^{22}$ On such proposals, our understanding of mental concepts is based on a tacit psychological theory which explains people's overt behaviour, and it is the status of this theory as the best explanation of the observed data which justifies beliefs about other people's mental lives. This form of explanation avoids the obstacle presented by the separation of sensation from behaviour by denying that our understanding of mental concepts need be based on sensation. There is no obstacle to acknowledging that one cannot learn what it is for another to be in pain from one's own case because one's own case plays no distinctive role in understanding mentality.

Nevertheless, although this move avoids the obstacle presented by the separation of sensation and behaviour, one might question whether our understanding of mentality can be wholly divorced from any experience of mental features. In particular, such a divorcement seems to remove from our understanding of the mental any aspect of its phenomenology. According to such accounts, our understanding of what it is to be in pain

22 See, in particular, [Putnam 1975]. Fodor would seem to endorse something along these lines: [Fodor 1987, p.x]. 
is exhausted by the propositions of the tacitly held theory: a theory which makes no reference to one's own case. But what role, then, does the painfulness of pain play in our understanding of the concept?

The concern expressed here is a version of the charge levelled against functionalist theories of the mental: that they lack the resources to explain the phenomenology of mental states and events. And with good reason: the view that our understanding of mentality is based solely on the workings of a tacit psychological theory is - both historically and philosophically - aligned with a functionalist view about the nature of mental states. ${ }^{23}$ And by denying any role for the experience of mentality in our understanding of mental concepts, such proposals fail to account for the phenomenological understanding involved in our grasp of mental concepts.

We have, then, an obstacle to the possibility of our thinking about other minds. In thinking about other minds we make use of a general conception of the mental. Any obstacle to the possession of such a conception serves as an obstacle to the possibility of such thought. We find in Wittgenstein the suggestion that the detachment of sensation from behaviour serves as such an obstacle. For if sensation and behaviour are wholly detached, then our sensations are not presented to us in such a way that we can use them to form a general conception of the mental. The presentation of such sensations makes no room for the thought that they might exist independently of my subjective consciousness.

How should we respond to this obstacle? According to what I will term the Embodiment response, the conclusion to draw from this discussion is that we should reject the claim that mental occurrences are not presented to us as aspects of a person. Instead, we should recognise that mental life presents its components as spatially and temporally located modes of our human person and thus as intimately bound up in our physical features. Since mental occurrences are presented as spatial and temporal aspects of our person, they are presented to us as the kinds of things which other people might enjoy or endure. It is recognition of the embodiment of our mental life which enables us to avoid the obstacle.

${ }^{23}$ Most obviously in the case of Putnam: [Putnam 1975]. 
The Embodiment response is supported by reflection on the phenomenology of mental sensations. As Bill Brewer puts it, '[w]e cannot get away from the fact that bodily sensations immediately appear as determinately located not only in egocentric space, but also in specific body-parts filling those locations' [Brewer 1999, p.299]. Since sensations are presented to us as spatial and temporal aspects of our person, the structure of our awareness of sensations mirrors the structure of the substantial representations used in ascribing sensations to others and to ourselves. Sensations are presented to us as the kinds of things which are predicated of persons. It is this form of awareness which explains our ability to think of sensations as aspects of a person.

One might object to this line of thought as follows: according to the Embodiment response, mental occurrences are presented to us as spatial and temporal aspects of persons. This is only plausible so long as one's attention is focused on the sensational aspects of the mental: pains, itches, tickles and the like. When one considers the non-sensational aspects of the mind such as beliefs, intentions and judgements, the Embodiment claim is much less convincing. Beliefs, intentions and judgements, although perhaps temporal, are not presented to us as spatially located about our person in the manner of pains and itches. So the Embodiment claim is only true of a subset of mental phenomena and thus at best can only explain our ability to think of other people as subject to the sensational aspects of mental life.

A concessive response to this objection would be to accept its contention but dispute its relevance. Let us accept that it is only sensations which are presented as spatial and temporal aspects of persons. According to the Embodiment response, this explains how it is possible to think of sensations as ascribable to other subjects. Does it follow that we have no way of explaining our ability to think of other people as subject to the non-sensational aspects of mentality? One suggestion is that once we can think of other people as subject to mental sensations, we can generate a wider conception of a subject of experience to whom other mental phenomena can be ascribed. It is the generation of this more formal notion of a subject of experience - a generation founded on our ability to think of 
others as subject to sensations - which explains our ability to think of others as the subject of non-sensational mental phenomena. ${ }^{24}$

A more aggressive response would be to question the claim that the nonsensational aspects of the mental are not presented to us as aspects of our person. It is true that they are not presented as spatially located in the manner of sensations, but there is still a sense in which it is part of the character of such episodes of thought that it is me that is doing the thinking. As the psychologist Frank Fish puts it in a discussion of schizophrenia, 'thinking, like all conscious activities, is experienced as an activity which is being carried out by the subject or, to use a clumsy German expression, there is a quality of 'my-ness' connected with thought.' [Fish 1976, p.39]. This is relevant if subjects are themselves presented as spatial and temporal beings, as Quassim Cassam has argued, for then episodes of thought are presented as aspects of spatial and temporal beings. ${ }^{25}$ This would be a way of extending the Embodiment response to take in the embodiment of non-sensational mental phenomena.

Let me recap the discussion. Our concern was the possibility of thinking about other minds, and this discussion enables us to formulate a conceptual problem. In thinking about other minds we make use of a general conception of the mental. The obstacle to possessing such a conception is the claim that mental phenomena form a self-standing realm independent of bodily behaviour: that sensation is distinct from behaviour. Given this claim, we cannot explain how the experience of such sensations could ground a general conception of the mental since the presentation of such sensation does not provide a viewpoint from which to distinguish the mental event happening from its happening to me. This result is a distinctive problem in the philosophy of mind which turns on the way in which our understanding of mental processes is grounded in our experience of mental life.

We can remove this obstacle by rejecting the claim that sensation and behaviour are distinct and holding instead that mental phenomena are presented as spatial and temporal aspects of our person. In virtue of being

24 [Pickard 2003, p.102] makes a similar claim with regard to the emotions. Note that this response implies that our basic conception of another person is as a subject of sensations, a claim that might be thought to be both developmentally and ontogenetically plausible.

25 [Cassam 1997] 
presented in this way, they are presented as the kinds of things which other subjects can enjoy or endure. The embodiment of mental phenomena provides us with a perspective from which to individuate sensations and think of them as the sort of things which could be present even when they are not being undergone. It is the significance of our embodied status which explains our capacity for thinking of others as having a viewpoint on the world.

\section{Other Persons}

How does this conceptual problem relate to the traditional epistemological problem of accounting for our knowledge of other minds? The epistemological problem of other minds is sometimes raised by appeal to cases of pretence and deception, but as Fodor's comment above suggests, this way of raising the problem fails to identify issues of distinctive sceptical concern. More importantly, it fails to engage with the way in which the problem has historically been pursued. As traditionally presented, what motivates the epistemological problem of other minds is not the possibility of certain sceptical situations but a concern with identifying the source of our knowledge of other minds. ${ }^{26}$

One can motivate the problem as follows. Say one thought that there were two broad ways by which we come to know about the world: through perception and by inference. One can then ask: is our knowledge of other minds perceptual or inferential? Against perception it is said that we cannot perceive the mind of another person but only her behaviour. So we cannot be said to have perceptual knowledge of her mental life. And against inference it is claimed that this experience of behaviour isn't secure enough to ground an inference to the presence of other minds. Standard responses to the epistemological problem opt to deny one or other of these claims: either they claim that perception can be a source of knowledge of other minds, or they claim that the experience of behaviour can ground inferential knowledge about another's mind. ${ }^{27}$

How does the conceptual problem of other minds bear on this debate? It is sometimes suggested by those who deny the separation of sensation and

${ }^{26}$ For examples of the problem being raised in this manner, see [Ayer 1953, p.193], [Stout 1898, p.14, p.20], [Price 1933, p.273].

27 [Duddington 1918-19] provides an early defence of the perceptual model; [Mill 1884] and [Russell 1948] use versions of the argument from analogy to defend the inferential model. 
behaviour that attention to the conceptual problem dissolves the epistemological problem of other minds. ${ }^{28}$ The reasoning seems to go as follows: knowledge of other minds only looks problematic if one assumes that our experience of other people falls short of their mentality. But my experience of another could only fall short of her mentality if there was an ontological gap between behaviour and sensation. Resolution of the conceptual problem requires rejecting such a gap. So resolution of the conceptual problem removes the reason for being concerned about knowledge of other minds.

The natural way to read this suggestion is as proposing a link between resolution of the conceptual problem and the endorsement of a perceptual model of knowledge of other minds. ${ }^{29}$ But one might be wary of drawing too tight a connection here. A minimal rejection of the gap between behaviour and sensation requires only that, in one's own case, sensations are presented as aspects of a spatially located person and thereby as intimately bound up in their behavioural manifestations. But there may be ways of accepting this non-contingent link between sensation and behaviour which fall short of according perceptibility to the mental lives of others. One might accept that mental states and events are presented to the subject as spatial aspects of her person whilst remaining neutral on the way in which those mental states and events are presented in perceptual experience. Claims about the relation of sensation to behaviour don't immediately have implications for the nature and objects of perceptual experience.

Nevertheless, there may be something more we can say. One of the issues raised by this presentation of the conceptual problem is, roughly, the question of how our mentality is presented to us. The reason why the detachment of sensation from behaviour is said to pose an obstacle to the possibility of possessing a general conception of the mental is that the presentation of such sensations cannot provide the material for making the distinctions involved in grasping such a conception. And in rejecting such a detachment, one is moved to acknowledge that sensations are not presented to us as distinct from their behavioural expressions: there is no pure point of view of consciousness. Rather, our mentality is presented to us as an aspect of our person: it as persons that we think and feel, hope and

28 [Malcolm 1954, p.976]

29 [McDowell 1982] can be seen in this light. 
love. Addressing the conceptual problem requires attention to the way in which our mentality is presented to us as bound up with its behavioural expression.

Why might this have implications for the epistemological problem? Questions about our knowledge of other people's mental lives tend to focus solely on the mental states and events under consideration: our concern is whether justification can be provided for my belief that a particular mental state or event is present. And if we confine ourselves to thinking only about such states and events - what Hornsby has called these 'micro-things' [Hornsby 1997, p.20, p.31] - it can seem mandatory to suppose that the competencies involved in our navigating the social world involve processes of inferential and theoretical reasoning. Detached from their role in the wider life of a person, these micro-entities seem hidden from view and thus only knowable as the result of an inference to the best explanation.

But one might wonder whether this picture of our social interaction can be sustained in light of the proposed resolution of the conceptual problem. Can an account of our knowledge of other minds conduct inquiries into our knowledge of other people's mental states and events without considering the subjects who undergo and instantiate these features? Resolution of the conceptual problem has drawn attention to the way in which mental phenomena are bound up with the behaviour and expressions of persons, yet actual, living, visible, audible people are notably absent from our discussions of such knowledge.

This line of thought recalls Jennifer Hornsby's suggestive comment that many problems in the philosophy of mind are 'attributable partly to a line of thinking which allows questions about consciousness to arise detached from questions about the beings that are actually conscious' [Hornsby 1997, p.17]. The problem is that 'a person's leading of a mental life is treated as if it were a separable side of her biography' [Hornsby 1997, p.44]. In the case of our knowledge of other minds, this thought might be expressed as follows: knowledge of other minds is made to look mysterious because we detach questions about how we know about other people's mental states and events from questions about how we know about the subjects of those mental features. Philosophical work in this area debates the problem of "other minds"; but one's own mind should be contrasted 
others' minds, just as one's own body is contrasted with others' bodies. ${ }^{30}$ Reflection on the conceptual problem of other minds should remind us that the problem of other minds is a problem about our relation to other people. $^{31}$

\section{References}

Avramides, A. (2001). Other Minds. London: Routledge.

Ayer, A.J. [1953] (1953). 'One's Knowledge of Other Minds'. Reprinted in his Philosophical Essays. London: Macmillan, pp.191-214

Brewer, B. (1995) 'Bodily Awareness and the Self, in B. Brewer, J. Bermúdez, A. Marcel and N. Eilan (eds.) The Body and the Self. Cambridge, MA: The MIT Press.

Brewer, B. (2002). 'Emotion and other minds' in P. Goldie (ed.) Understanding Emotions: Mind and Morals. Aldershot: Ashgate, pp.2336.

Cassam, Q. (1997) Self and World. Oxford: Oxford University Press

Cassam, Q. (2007) The Possibility of Knowledge. Oxford: Oxford University Press.

Davidson, D. [1987] (2006). 'Knowing One's Own Mind'. Reprinted in his Subjective, Intersubjective, Objective. Oxford: Oxford University Press.

Dretske, F. (1973). 'Perception and Other Minds', Noûs 7: pp34-44.

Duddington, N. A. (1918). 'Our Knowledge of Other Minds', Proceedings of the Aristotelian Society, 19: pp.147-178.

Evans, G. (1982). The Varieties of Reference. Oxford: Clarendon Press.

Fish, F. (1976) Fish's schizophrenia, 2nd edn. Bristol: J. Wright.

Fodor, J. (1987). Psychosemantics. Cambridge MA, MIT Press.

Guttenplan, S. (ed.) (1994) A Companion to the Philosophy of Mind. Oxford: Blackwell.

Hornsby, J. (1997) Simple mindedness: in defense of naïve naturalism in the philosophy of mind. Cambridge, MA: Harvard University Press

\footnotetext{
30 Annette Baier points this out in her [Baier 1994].

${ }^{31}$ Very many thanks to Jennifer Hornsby, Nick Jones, Rory Madden, Will McNeill and Komarine Romdenh-Romluc for comments on earlier versions of this paper; my thanks also to those present at the meeting of the Aristotelian Society for their questions and comments.
} 
Malcolm, N. (1954). 'Wittgenstein's Philosophical Investigations', Philosophical Review 63 (4):530-9.

Malcolm, N. (1958). 'Knowledge of Other Minds', Journal of Philosophy 55: pp.35-52.

McDowell, J. [1982] (1998). 'Criteria, Defeasibility and Knowledge'. Reprinted in his Meaning, Knowledge and Reality. Cambridge MA: Harvard University Press: 369-94.

McGinn, C. (1984). 'What is the Problem of Other Minds?' Proceedings of the Aristotelian Society, Supplementary Volume 58, 119-137.

Mill, J.S. [1884] (1979). An Examination of Sir William Hamilton's Philosophy, ed. J.M. Robson and A. Ryan. Toronto: University of Toronto Press.

Nozick, R. (1981). Philosophical Explanations. Cambridge, MA: Harvard University Press.

Overgaard, S. (2007). Wittgenstein and Other Minds: Rethinking Subjectivity and Intersubjectivity with Wittgenstein, Levinas, and Husserl. London: Routledge.

Pears, D. (1988) The False Prison: Volume Two. Oxford: Oxford University Press

Pears, D. (2006). Paradox and Platitude in Wittgenstein's Philosophy. Oxford: Oxford University Press

Pickard, H. (2003). 'Emotions and the Problem of Other Minds' in: A. Hatzimoysis (ed.) Philosophy and the Emotions. Cambridge: Cambridge University Press, 87-103.

Price, H.H. (1933). 'Mr. W.T. Stace on the Construction of the External World', Mind 42: 167, pp. 273-298.

Putnam, H. (1975). 'Other Minds'. Reprinted in his Mind, Language and Reality: Philosophical Papers vol. 2. Cambridge: Cambridge University Press.

Russell, B. (1948). Human Knowledge: Its Scope and Limits. London: Routledge.

Ryle, G. (1949). The Concept of Mind. London: Hutchinson.

Stout, GF. (1898). Manual of Psychology. University Correspondence College Press: London.

Strawson, P.F. (1959). Individuals. London: Routledge.

Strawson, P.F. (1966) The Bounds of Sense. London: Methuen \& Co.

Strawson, P.F. [1976] (1997). 'Entity and Identity'. Reprinted in his Entity and Identity: and other essays. Oxford: Oxford University Press.

Stroud, B. (1968). 'Transcendental Arguments', Journal of Philosophy 65: pp.241-56

Williams, B. (1978). Descartes: The Project of Pure Enquiry. London: Penguin.

Wittgenstein, L. (1953) Philosophical Investigations. Oxford: Basil Blackwell 